\title{
Effect of Precipitation on the Hardness of Ternary Metallic Glass
}

\author{
Xue Liang1*, Jiuhua Chen ${ }^{1,2}$, Maria Teresa Mora', Jose Fernandez Urdaneta1, Qiaoshi Zeng² \\ ${ }^{1} \mathrm{MME} / \mathrm{CeMSEC}$, Florida International University, EC, Miami, FL, USA \\ ${ }^{2}$ Center for High Pressure Science and Technology Advanced Research, Changchun, China \\ Email: ${ }^{*}$ xlian002@fiu.edu
}

How to cite this paper: Liang, X., Chen, J.H., Mora, M.T., Urdaneta, J.F. and Zeng, Q.S. (2017) Effect of Precipitation on the Hardness of Ternary Metallic Glass. Advances in Materials Physics and Chemistry, 7, 255-262.

https://doi.org/10.4236/ampc.2017.76020

Received: May 1, 2017

Accepted: June 12, 2017

Published: June 15, 2017

Copyright $\odot 2017$ by authors and Scientific Research Publishing Inc. This work is licensed under the Creative Commons Attribution International License (CC BY 4.0).

http://creativecommons.org/licenses/by/4.0/

\section{Open Access}

\begin{abstract}
The present study reports effects of annealing treatment on the hardness of $\mathrm{Ce}_{75} \mathrm{Al}_{23} \mathrm{Si}_{2}$ rare earth-based metallic glasses (REMG). Then specimens were annealed at $100^{\circ} \mathrm{C}, 200^{\circ} \mathrm{C}, 250^{\circ} \mathrm{C}, 270^{\circ} \mathrm{C}$, and $290^{\circ} \mathrm{C}$ five different temperatures for 30 minutes. After that, three different characteristic methods, including microindentation, X-ray Diffraction (XRD), and scanning electrical microscope (SEM) were conducted on the as received REMG sample and five annealed samples. XRD data demonstrate that the crystallization occurs in the sample at the annealing temperature as low as $200^{\circ} \mathrm{C}$. The microindentation measurement shows that hardness of the REMG sample does not change at all before crystallization occurs in the sample and increases with the annealing temperature in the range of $200^{\circ} \mathrm{C}$ to $290^{\circ} \mathrm{C}$. The average crystal size in the annealed samples was estimated using Debye-Scherrer equation to be 28-42 $\mathrm{nm}$, in consistent with the SEM observation, indicating that nano-crystalline domains may give rise to the enhancement of hardness.
\end{abstract}

\section{Keywords}

Ternary, Rare Earth-Based Metallic Glasses (REMGs), Microindentation, Annealing Treatment, Hardness

\section{Introduction}

Metallic glasses (MGs) attract plenty of interests regarding their special mechanical, acoustic, elastic and magnetic properties [1] [2] [3] [4]. Among these properties, the superior mechanical properties of MGs or bulk metallic glasses (BMGs) are the most promising for engineering applications considering the lack of dislocation mechanism for plastic deformation [5] [6] [7]. Also, MGs are used in high efficiency transformers regarding their soft-magnetic properties due to the absence of a magneto-crystalline anisotropy. Besides the mentioned 
properties, high resistance to corrosion is another impressive property of MGs [8]. Thus, BGMS or coated MGs can be used in very aggressive environments with the combined strong wear resistance ability and corrosion resistance ability. In previous studies, various preparation methods have been developed to produce MGs. One of the general guiding principles of designing MGs is to choose elements with large differences in size, which leads to a complex structure that crystallizes less easily. Recently, the rare earth (RE) elements such as cerium (Ce), lutetium ( $\mathrm{Lu})$, neodymium $(\mathrm{Nd})$, yttrium $(\mathrm{Y})$ and lanthanum (La) have been used as critical alloying additions or basic constituent to improve the performance of BMGs [9]. The Ce-based rare earth bulk metallic glass with lower glass transition temperature and special mechanical properties such as lower elastic modulus was reported in one previous study [10].

Cerium is the most abundant of all the lanthanide among the earth crust and it occurs in various minerals [11]. Ce can replace $\mathrm{Zr}$ as the based constituent material during $\mathrm{BMG}$ preparing since they have a similar atom structure. Ce-based MGs i.e., $\mathrm{Ce}_{55} \mathrm{Al}_{45}$ and $\mathrm{Ce}_{75} \mathrm{Al}_{25}$, have been successfully prepared and unique properties, i.e., pressure induced polyamorphism, have been reported in these kinds of MGs [10] [12] [13] [14]. One possible mechanism was that the $4 f$ electron delocalization in Ce under high pressure causes bond shortening. This electronic polyamorphism is very different from the structural polyamorphism compared with other amorphous materials. Moreover, electronic structure of $\mathrm{Ce}$ in Ce-bearing materials can not only be changed by pressure but also by alloying with other elements. Zeng et al. reported that the minor alloying effect, i.e., Si doping in the $\mathrm{Ce}_{75} \mathrm{Al}_{25}$ MG system, which can change the transition pressure even properties of both high-density amorphous (HAD) and low-density amorphous (LDA) of $\mathrm{Ce}_{75} \mathrm{Al}_{23} \mathrm{Si}_{2}$ metallic glass obviously [11] [14].

To characterize the mechanical performances of bulk metallic glasses, both standard or customized tensile tests and indentation test have been conducted. However, the tensile test would require special care for sample preparation, especially for MGs which are mostly prepared in foil or powder rather than large bulks (i.e., $25.4 \mathrm{~mm}$ length and $6.35 \mathrm{~mm}$ width). Thus, the multi-scaling indentation are more favored for studying MGs to examine both the macro/micro mechanical response via hardness and the deformation zones around/underneath the indent [13] [14]. However, in many other experiments, roughly semicircular shear bands were observed which are not predicted by the slip-line theory. These shear bands and their associated hemispherical plastic zone beneath the indent were explained using the expanding cavity model. Also, previous studies have demonstrated that annealing-induced hardening might be possible in bulk metallic glasses (BMG) [9] [15]. Multi-scaling indentation as well as different inverse methods can be utilized to access the elastic properties [16] and plastic properties of individual grains [17] [18] and individual phases [19]. Besides, the application of multi-direction indentation will be helpful to understand the possible anisotropy of REMGs foils [20]. So far, there have not been any reports on the annealing effects on the mechanical properties of REMGs. 
Our aim is to examine the influence of annealing on the mechanic properties of melt-spun glassy $\mathrm{Ce}_{75} \mathrm{Al}_{23} \mathrm{Si}_{2}$ ribbons. In this paper, we applied the microindentation in REMGs to correlate the mechanical performances and annealing temperatures. The XRD and SEM are followed to illustrate the evolution of the structure and the element distributions. The understanding of annealing effects on the mechanical behaviors of these alloys will be fruitful for further research.

\section{Experiments}

\subsection{Sample Preparation}

All master ingots were prepared by arc-melting a mixture of pure Ce (99.5 at\%), $\mathrm{Al}$ (99.95 at\%), Si (99.99 at.\%) in a Zirconium-gettered argon atmosphere. Each ingot was melted five times to ensure homogeneity in composition. Using these master ingots, thin ribbon $\mathrm{Ce}_{75} \mathrm{Al}_{23} \mathrm{Si}_{2}$ (the numbers present atomic percentage) metallic glass with a thickness of about $\sim 35 \mu \mathrm{m}$ and a width of $\sim 3 \mathrm{~mm}$ was further prepared via single-roller melt-spinning with a $\mathrm{Cu}$ wheel surface rotating speed of $40 \mathrm{~m} / \mathrm{s}$ as shown in Figure 1. Then, the ribbon was divided into six pieces, with each piece $5 \mathrm{~mm} * 2 \mathrm{~mm} * 35 \mu \mathrm{m}$. Each $\mathrm{Ce}_{75} \mathrm{Al}_{23} \mathrm{Si}_{2}$ metallic glass sample was loaded in quartz capillary and kept under vacuum at $4 \times 10^{-4}$ Torr to reduce the possibility of oxidation in annealing heat treatment. A Fisher Scientific oven was used to heat the sample at $100^{\circ} \mathrm{C}, 200^{\circ} \mathrm{C}, 250^{\circ} \mathrm{C}, 270^{\circ} \mathrm{C}$ and $290^{\circ} \mathrm{C}$ for $30 \mathrm{~min}$, respectively.

\subsection{Materials Characterization}

The X-ray diffraction studies were carried out using Bruker GADDS/D8 X-ray facility with molybdenum MacSci rotating anode, $\lambda$ is $0.709319 \AA$ and Apex Smart CCD at Center for the Study of Matter at Extreme Conditions (CeSMEC), FIU. The XRD patterns were collected for 5 minutes for each sample and the diffraction angle 2-thera range was set to 35 degrees. The SEM studies were car-

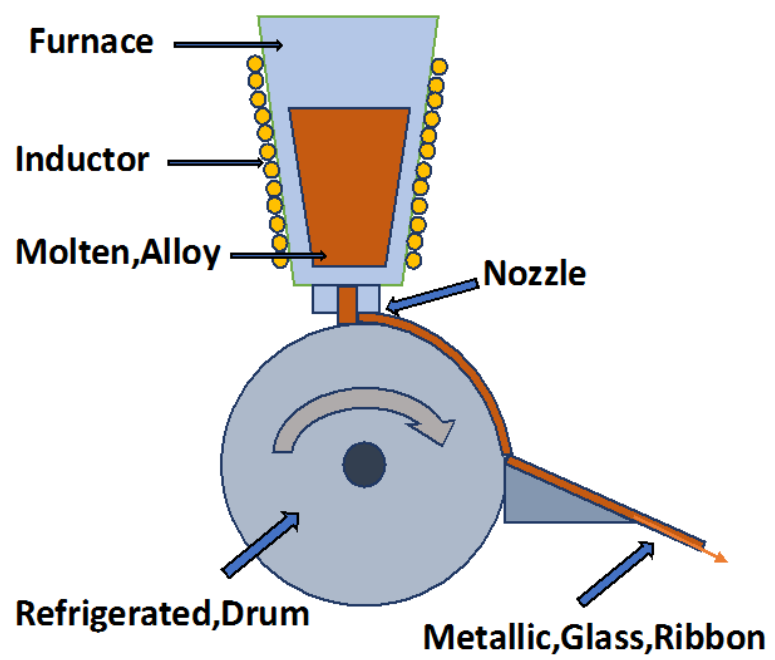

Figure 1. Processing of $\mathrm{Ce}_{75} \mathrm{Al}_{23} \mathrm{Si}_{2}$ metallic glass preparation using single-roller melt-spinning method. 
ried out by using JEOL 6330 equipped with a Noran System Six EDS analyzer. The hardness of the samples was measured using the LECO's LM Microindentation Hardness Testing System. The surface of the MGs is polished using a standard processing to reduce the surface roughness. The microindentation tests were carried out at $25 \mathrm{~g}$ loads and a $10 \mathrm{~s}$ dwelling time on all samples. Nine Vickers indentations were placed on each sample with a three by three array and sufficient space was kept between indents to avoid the potential plastic deformation zone overlapping. The averaged hardness values and the deviations of the six samples were calculated. Both SEM and microindentation were performed at the Advanced Materials Engineering Research Institute (AMERI).

\section{Results and Discussions}

Figure 2 shows the result of hardness measurement for the six samples of different annealing conditions. The initial hardness for the sample as received was around $200 \mathrm{HV}$ and this value remained nearly unchanged for the sample annealed at $100^{\circ} \mathrm{C}$. When the annealing temperature was increased to $200^{\circ} \mathrm{C}$, the hardness increased by $\sim 10 \%$ to $220 \mathrm{HV}$. However, the hardness increased to 310 $\mathrm{HV}$, which is $\sim 50 \%$ higher compared to the as received samples when the annealing temperature was raised to $250^{\circ} \mathrm{C}$. Finally, the average hardness of the annealed sample reached $\sim 400 \mathrm{HV}$ after treated at $290^{\circ} \mathrm{C}$.

Figure 3 shows X-ray diffraction patterns of the specimens before and after the annealing at diffraction conditions. No sharp peaks were observed for the as received sample and the pattern is identical to that of the REMG with the same composition [11] and similar to that of $\mathrm{Ce}_{75} \mathrm{Al}_{25}$ [14]. Singh et al. [10] studied $\mathrm{Ce}_{75} \mathrm{Al}_{25-\mathrm{x}} \mathrm{Ga}_{\mathrm{x}}$ metallic glasses and found that incorporation of small amount of $\mathrm{Ga}(\mathrm{x}=2)$ may introduce a new major diffraction peak at a higher angle but appearance of such a new peak was not observed in the case of Si incorporation

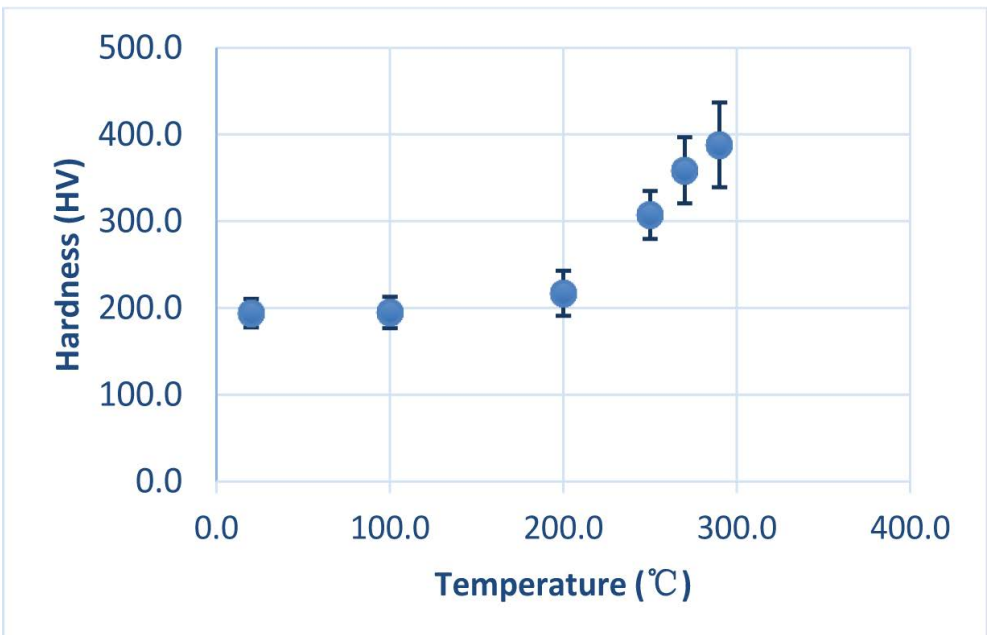

Figure 2. The average hardness values (HV) of each sample with different annealing temperatures (The points from left to right were the as received sample and samples annealing at $100^{\circ} \mathrm{C}, 200^{\circ} \mathrm{C}, 250^{\circ} \mathrm{C}, 270^{\circ} \mathrm{C}$, and $290^{\circ} \mathrm{C}$ ). Bars attached to the symbols represent the experimental uncertainty. 


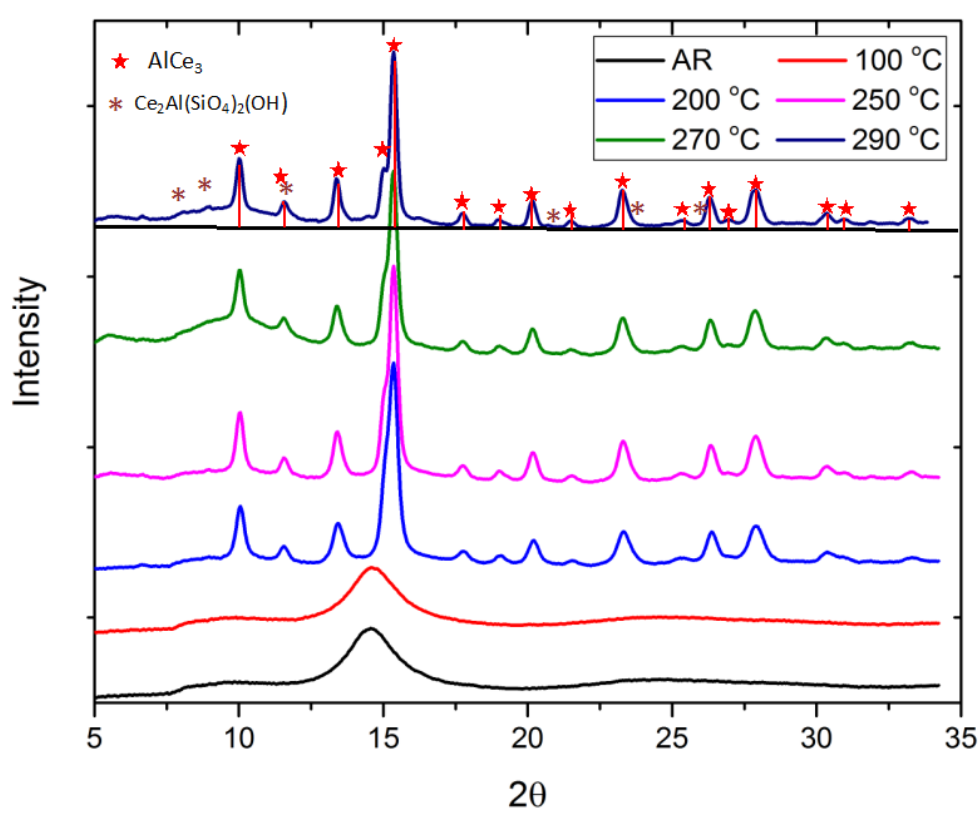

Figure 3. The XRD patterns of each samples: (a) as received (AR) sample; (b) sample annealed at $100^{\circ} \mathrm{C}$, (c) sample annealed at $200^{\circ} \mathrm{C}$; (d) sample annealed at $250^{\circ} \mathrm{C}$; (e) sample annealed at $270^{\circ} \mathrm{C}$; and (f) sample annealed at $290^{\circ} \mathrm{C}$ (Wavelength $\lambda$ is $0.7093 \AA$, exposure time is $300 \mathrm{sec}$.)

with the same amount $(x=2)$. The diffraction pattern of the sample annealed at $100^{\circ} \mathrm{C}$ did not show any significant change compared to that of the as received sample, indicating no crystallization at this annealing temperature. Upon annealing at higher temperatures, sharp crystalline diffraction peaks were observed. All the observed peaks were identified belonging to the hexagonal $\alpha$ $\mathrm{AlCe}_{3}$ phase.

The average crystallite sizes of the annealed samples were estimated based on the diffraction data using Debye-Scherrer equation [21] as shown below

$$
\beta=\frac{K \lambda}{d \cos \theta}
$$

where $\beta$ is full width at half maximum (FWHM) of the diffraction peak, $\mathrm{K}$ is a dimensionless shape factor with a value close to unity but may vary from 0.9 to 1.1 depending on the actual shape of the crystallite ( $K=1$ is used here), $\lambda$ represents the wavelength of X-ray source ( $0.7093 \AA$ used in this experiment), $d$ is the average grain size and $\theta$ is the Bragg angle of the diffraction peak. The FWHM of each diffraction pattern was obtained through curve fitting using Fityk [22], and the average crystallite sizes were derived to be $28,31,33$, and 42 $\mathrm{nm}$ for the samples annealed at $200^{\circ} \mathrm{C}, 250^{\circ} \mathrm{C}, 270^{\circ} \mathrm{C}$ and $290^{\circ} \mathrm{C}$ respectively. The SEM micrograph (Figure 4) confirms that the crystallite sizes are in such a nanometer range. According the Hall-Petch relationship for yield strength $\left(\sigma_{y}\right)$ of a crystalline sample, i.e. $\sigma_{y}=\lambda_{0}+k_{y} d^{-1 / 2}$, the increase of crystallite sizes (d) may result in a decrease in strength. Regarding the linear relationship, the microhardness values can be converted to the $\sigma_{r y}$ [23] [24] Using $\lambda_{o}=255 \mathrm{Hv}$ (the hardness for $\mathrm{Ce}_{75} \mathrm{Al}_{25}$ metallic glass measured with $25 \mathrm{~g}$ load [10] and $k_{y}$ 


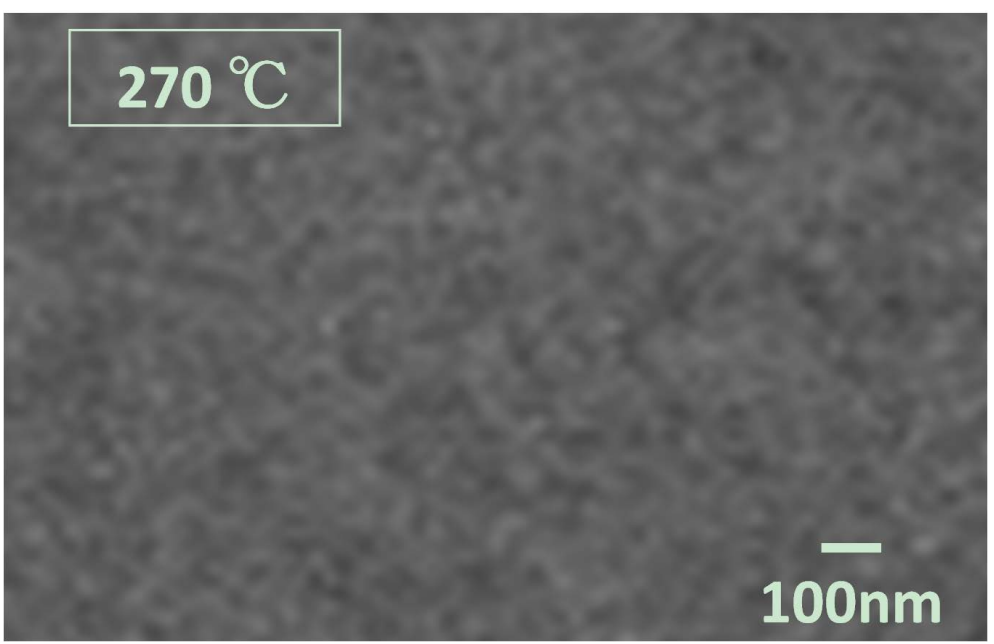

Figure 4. The backscatter SEM of $\mathrm{Ce}_{75} \mathrm{Al}_{23} \mathrm{Si}_{2} \mathrm{MG}$ after annealing at $270^{\circ} \mathrm{C}$.

value from 2 to $5 \mathrm{MPa} \mathrm{m}{ }^{1 / 2}$ for the estimation of Hall-Petch effect [25], the hardness is expected to decrease by about $15 \%-17 \%$ when the crystallite sizes increases from 28 to $42 \mathrm{~nm}$. Therefore, the fact that the bulk hardness increases by more than $50 \%$ is dominantly influenced by the population increase of the crystalline precipitation, not by the change in the size of such precipitation at higher annealing temperature.

Although the crystalline alloy is in general softer than the metallic glass of the same composition, grain boundaries and the statistically stored dislocations (SSDs) in the crystalline grains near the interfaces between amorphous alloy and the new generated nanocrystal serve as barriers to the plastic deformation and hence increase the hardness of the bulk with nano-size precipitations. As more $\mathrm{AlCe}_{3}$ phase precipitates at higher the annealing temperature, Si bearing phase becomes visible in the diffraction patterns. The weak diffraction peaks in the pattern of $290^{\circ} \mathrm{C}$ annealed sample in Figure 3 were identified as Cerium Aluminum Silicate Hydroxide $\left[\mathrm{Ce}_{2} \mathrm{Al}\left(\mathrm{SiO}_{4}\right)_{2}(\mathrm{OH})\right]$. This is in consistent with the increase in $\mathrm{AlCe}_{3}$ phase as the annealing temperature rises. Nevertheless, a decrease of the hardness is expected if the crystallization is complete and bulk sample dominated by $\mathrm{AlCe}_{3}$ crystalline phase of larger crystallite sizes at high enough annealing temperature or long enough annealing time.

\section{Conclusions}

Annealing of the $\mathrm{Ce}_{75} \mathrm{Al}_{23} \mathrm{Si}_{2}$ REMG at a temperature above $200^{\circ} \mathrm{C}$ introduces nano $\mathrm{AlCe}_{3}$ crystalline precipitations of about $30-40 \mathrm{~nm}$, which in turn enhances the hardness of the annealed system. The population of such nano precipitations increases with the annealing temperature within the range of $200^{\circ} \mathrm{C}$ $290^{\circ} \mathrm{C}$. Consequently, the bulk hardness also increases with the annealing temperature. The hardness enhancement, however, is restricted to a limited range of annealing temperature and annealing time. Further experiments beyond the current range of annealing temperature and time, and more detailed microstructure studies using e.g. TEM will be helpful to completely understand the 
process.

\section{Acknowledgements}

The authors are thankful to Dr. Alexander Franco and Dr. Vadym Drozd for their technical assistance. Part of this research was carried out by AMERI, Florida International University. The work was partially supported by NSAF Grant No. U1530402.

\section{References}

[1] Luo, Q., Zhao, D., Pan, M. and Wang, W. (2006) Magnetocaloric Effect in Gd-Based Bulk Metallic Glasses. Applied Physics Letters, 89, Article ID: 081914. https://doi.org/10.1063/1.2338770

[2] Louzguine, D.V. and Inoue, A. (2001) Electronegativity of the Constituent RareEarth Metals as a Factor Stabilizing the Supercooled Liquid Region in Al-Based Metallic Glasses. Applied Physics Letters, 79, 3410-3412. https://doi.org/10.1063/1.1420781

[3] Rosenflanz, A., Frey, M., Endres, B., Anderson, T., Richards, E. and Schardt, C. (2004) Bulk Glasses and Ultrahard Nanoceramics Based on Alumina and RareEarth Oxides. Nature, 430, 761-764. https://doi.org/10.1038/nature02729

[4] Inoue, A. (2000) Stabilization of Metallic Supercooled Liquid and Bulk Amorphous Alloys. Acta Materialia, 48, 279-306. https://doi.org/10.1016/S1359-6454(99)00300-6

[5] Telford, M. (2004) The Case for Bulk Metallic Glass. Materials Today, 7, 36-43. https://doi.org/10.1016/S1369-7021(04)00124-5

[6] Löffler, J.F. (2003) Bulk Metallic Glasses. Intermetallics, 11, 529-540. https://doi.org/10.1016/S0966-9795(03)00046-3

[7] Wang, W.-H., Dong, C. and Shek, C. (2004) Bulk Metallic Glasses. Materials Science and Engineering: R: Reports, 44, 45-89. https://doi.org/10.1016/j.mser.2004.03.001

[8] Johnson, W.L. (1999) Bulk Glass-Forming Metallic Alloys: Science and Technology. MRS Bulletin, 24, 42-56. https://doi.org/10.1557/S0883769400053252

[9] Gu, J., Song, M., Ni, S., Guo, S. and He, Y. (2013) Effects of Annealing on the Hardness and Elastic Modulus of a $\mathrm{Cu}_{36} \mathrm{Zr}_{48} \mathrm{Al}_{8} \mathrm{Ag}_{8}$ Bulk Metallic Glass. Materials \& Design, 47, 706-710. https://doi.org/10.1016/j.matdes.2012.12.071

[10] Singh, D., Singh, D., Mandal, R., Srivastava, O. and Tiwari, R. (2014) Glass Forming Ability, Thermal Stability and Indentation Characteristics of $\mathrm{Ce}_{75} \mathrm{Al}_{25-\mathrm{x}} \mathrm{Ga}_{\mathrm{x}}$ Metallic Glasses. Journal of Alloys and Compounds, 590, 15-20. https://doi.org/10.1016/j.jallcom.2013.11.234

[11] Zeng, Q., Fang, Y., Lou, H., Gong, Y., Wang, X., Yang, K., Li, A., Yan, S., Lathe, C. and $\mathrm{Wu}, \mathrm{F}$. (2010) Low-Density to High-Density Transition in $\mathrm{Ce}_{75} \mathrm{Al}_{23} \mathrm{Si}_{2}$ Metallic Glass. Journal of Physics. Condensed Matter, 22, Article ID: 375404. https://doi.org/10.1088/0953-8984/22/37/375404

[12] Singh, D., Singh, D., Srivastava, O. and Tiwari, R. (2016) Microstructural Effect on the Low Temperature Transport Properties of Ce-Al (Ga) Metallic Glasses. Scripta Materialia, 118, 24-28. https://doi.org/10.1016/j.scriptamat.2016.03.007

[13] Duarte, M.J., Bruna, P., Pineda, E., Crespo, D., Garbarino, G., Verbeni, R., Zhao, K., Wang, W.H., Romero, A.H. and Serrano, J. (2011) Polyamorphic Transitions in Ce-Based Metallic Glasses by Synchrotron Radiation. Physical Review B, 84, Article 
ID: 224116. https://doi.org/10.1103/PhysRevB.84.224116

[14] Zeng, Q., Struzhkin, V.V., Fang, Y., Gao, C., Luo, H., Wang, X., Lathe, C., Mao, W.L., Wu, F. and Mao, H.-K. (2010) Properties of Polyamorphous $\mathrm{Ce}_{75} \mathrm{Al}_{25}$ Metallic Glasses. Physical Review B, 82, Article ID: 054111. https://doi.org/10.1103/PhysRevB.82.054111

[15] Xie, S. and George, E.P. (2008) Hardness and Shear Band Evolution in Bulk Metallic Glasses after Plastic Deformation and Annealing. Acta Materialia, 56, 5202-5213. https://doi.org/10.1016/j.actamat.2008.07.009

[16] Oliver, W.C. and Pharr, G.M. (1992) An Improved Technique for Determining Hardness and Elastic Modulus Using Load and Displacement Sensing Indentation Experiments. Journal of Materials Research, 7, 1564-1583. https://doi.org/10.1557/JMR.1992.1564

[17] Cheng, G., Barker, E.I., Stephens, E.V., Choi, K.S. and Sun, X. (2016) Quantifying Grain Level Stress-Strain Behavior for AM40 via Instrumented Microindentation. MRS Advances, 1, 761-772. https://doi.org/10.1557/adv.2016.25

[18] Cheng, G., Zhang, F., Ruimi, A., Field, D.P. and Sun, X. (2016) Quantifying the Effects of Tempering on Individual Phase Properties of DP980 Steel with Nanoindentation. Materials Science and Engineering: A, 667, 240-249.

https://doi.org/10.1016/j.msea.2016.05.011

[19] Cheng, G., Choi, K.S., Hu, X. and Sun, X. (2016) Determining Individual Phase Properties in a Multi-Phase Q\&P Steel Using Multi-Scale Indentation Tests. Materials Science and Engineering: A, 652, 384-395.

https://doi.org/10.1016/j.msea.2015.11.072

[20] Cheng, G., Sun, X., Wang, Y., Tay, S.L. and Gao, W. (2017) Nanoindentation Study of Electrodeposited Ag Thin Coating: An Inverse Calculation of Anisotropic Elastic-Plastic Properties. Surface and Coatings Technology, 310, 43-50. https://doi.org/10.1016/j.surfcoat.2016.12.056

[21] Mao, W.L., Struzhkin, V.V., Baron, A.Q., Tsutsui, S., Tommaseo, C.E., Wenk, H.R., Hu, M.Y., Chow, P., Sturhahn, W., Shu, J., et al. (2008) Experimental Determination of the Elasticity of Iron at High Pressure. Journal of Geophysical Research: Solid Earth, 113, B09213.

[22] Wojdyr, M. (2010) Fityk: A General-Purpose Peak Fitting Program. Journal of Applied Crystallography, 43, 1126-1128. https://doi.org/10.1107/S0021889810030499

[23] Rice, P.M. and Stoller, R.E. (2000) Correlation of Nanoindentation and Conventional Mechanical Property Measurements. MRS Proceedings, Cambridge University Press, Cambridge, Q7.11.

[24] Rodriguez, R. and Gutierrez, I. (2003) Correlation between Nanoindentation and Tensile Properties Influence of the Indentation Size Effect. Materials Science and Engineering: A, 361, 377-384. https://doi.org/10.1016/S0921-5093(03)00563-X

[25] Armstrong, R.W. (2014) 60 Years of Hall-Petch: Past to Present Nano-Scale Connections. Materials Transactions, 55, 2-12.

https://doi.org/10.2320/matertrans.MA201302 
Submit or recommend next manuscript to SCIRP and we will provide best service for you:

Accepting pre-submission inquiries through Email, Facebook, LinkedIn, Twitter, etc. A wide selection of journals (inclusive of 9 subjects, more than 200 journals)

Providing 24-hour high-quality service

User-friendly online submission system

Fair and swift peer-review system

Efficient typesetting and proofreading procedure

Display of the result of downloads and visits, as well as the number of cited articles Maximum dissemination of your research work

Submit your manuscript at: http://papersubmission.scirp.org/

Or contact ampc@scirp.org 